\title{
Studies on ADS as a neutron source at the Kyoto University Research Reactor Institute
}

\section{$\operatorname{AUTHOR}(\mathrm{S}):$}

Yoshiie, T.; Fukumoto, K.; Ishi, Y.; Ito, D.; Kuriyama, Y.; Misawa, T.; Mori, Y.; ... Shibata, S.; Uesugi, T.; Xu, $\mathrm{Q}$.

\section{CITATION:}

Yoshiie, T....[et al]. Studies on ADS as a neutron source at the Kyoto University Research Reactor Institute. Journal of Nuclear Materials 2014, 450(1-3): 16-19

\section{ISSUE DATE:}

2014-07

URL:

http://hdl.handle.net/2433/188899

\section{RIGHT:}

(C) 2014 Elsevier B.V.; This is not the published version. Please cite only the published version.; この論文は出版社版でありません。引用の際に は出版社版をご確認ご利用ください。 
Studies on ADS as a neutron source

at the Kyoto University Research Reactor Institute

T. Yoshiie ${ }^{(1)^{*}}$, K. Fukumoto ${ }^{(2)}$, Y. Ishi ${ }^{(1)}$, D. Ito ${ }^{(1)}$, Y. Kuriyama ${ }^{(1)}$, T. Misawa ${ }^{(1)}$, Y. Mori ${ }^{(1)}$, T. Nagasaka ${ }^{(3)}$, K. Nakajima ${ }^{(1)}$, Y. Oki ${ }^{(1)}$, C.H. Pyeon ${ }^{(1)}$, Y. Saito ${ }^{(1)}$, K. Sato ${ }^{(1)}$, X.Z. Shen ${ }^{(1)}$, S. Shibata ${ }^{(1)}$, T. Uesugi ${ }^{(1)}$ and Q. $\mathrm{Xu}^{(1)}$

${ }^{(1)}$ Kyoto University, Kumatori, Sennan, Osaka 590-0494, Japan

${ }^{(2)}$ University of Fukui, 4-2-1, Tsuruga 914-0055, Japan

${ }^{(3)}$ National Institute for Fusion Science, Oroshi, Toki 509-5292, Japan

\begin{abstract}
For developing an accelerator-driven system (ADS), many studies, such as those on accelerator development, subcritical system neutronics, materials irradiation effects, and thermal hydraulics, are required. In the Research Reactor Institute at Kyoto University (KURRI), an ADS is planned as a future neutron source. Recent activities of relevant ADS studies at KURRI are introduced herein.
\end{abstract}

Key words: Proton irradiation, Spallation, ADS, subcritical reactor, thermo hydraulics

Corresponding author: Toshimasa YOSHIIE

e-mail: yoshiie@ri.kyoto-u.ac.jp

tel: $+81-72-451-2473$

fax: $+81-72-451-2658$ 


\section{Introduction}

An accelerator-driven system (ADS) is a coupling of a subcritical nuclear reactor with a proton accelerator. High-energy protons irradiated into a target produce a large number of neutrons. These neutrons are used for energy generation as a neutron source and for transmutation of minor actinides in high-level waste from light water reactor fuels.

In the Research Reactor Institute at Kyoto University (KURRI), the construction of an ADS is planned as a future neutron source for irradiation experiments and neutron-scattering studies. Research activities relating to this have been performed for years. In particular, from 2002 to 2009, the MEXT (Ministry of Education, Culture Sports, Science and Technology, Japan) supported the "Research and Development for an Accelerator-Driven Sub-critical System Using an FFAG Accelerator" program. The main purpose of the studies was to perform basic feasibility evaluations of ADS as an energy production source. For this project, the Kyoto University Critical Assembly (KUCA) was used for the subcritical system and a newly developed Fixed-Field Alternating-Gradient (FFAG) synchrotron was installed.

The first injection of spallation neutrons into a uranium-loaded KUCA, a coupling of a subcritical nuclear reactor with the FFAG proton accelerator, was accomplished in March 2009 [1]. For the establishment of an ADS neutron source, four studies are now in progress: 1) Upgrade of the FFAG accelerator system, 2) ADS experiments using the subcritical reactor, 3) materials irradiation effect studies using high-energy protons; and 4) thermal hydraulics under proton irradiation. In this paper, recent research activities in these areas are introduced.

\section{FFAG accelerator}

Accelerators based on the FFAG principle have a unique feature in that non-linear magnetic fields can be utilized effectively, which is different from ordinary accelerators [2]. Non-linear beam dynamics is one of the most interesting subjects for this type of accelerator. Various novel accelerator ideas and technologies based on the FFAG principle such as ionization beam cooling, which could be useful for an intense neutron source, are also under development. The first KURRI-FFAG accelerator complex consisted of three circular accelerators; the injector ring, the booster ring, and the main ring. All three rings adopted the FFAG focusing scheme [3]. Recently, for increasing the proton beam current, the injector and the booster rings were taken off and an 11-MeV linear accelerator ( $\mathrm{H}^{-}$ions) was connected, as shown in Fig. 1. The main parameters in the present FFAG accelerator are listed in Table 1. An upgrade of the accelerating voltage of protons to $150 \mathrm{MeV}$ was performed in October 2012.

At present, the averaged beam current is $10 \mathrm{nA}$, which is limited by radiation safety restrictions but enough for the ADS experiment. The FFAG proton accelerator provides a pulsed beam where the beam pulse width is extremely short $(\sim 20 \mathrm{nsec})$. Since the peak beam power reaches $7.5 \mathrm{MW}$ or more, which is the same level as in practical ADS of about $20 \mathrm{MW}$, the experiment with FFAG and KUCA at Kyoto University provides a good field to study the dynamic phenomena of reactor physics 
for ADS including the development of neutron diagnostics.

\section{Subcritical reactor}

The KUCA is a multi-core type critical assembly established in 1974 as a facility for joint use for studies in reactor physics for researchers from universities all over Japan. It has three independent cores, two solid moderated cores (A, B cores) and one light water-moderated core ( $\mathrm{C}$ core). Basic studies on reactor physics and reactor engineering have been performed at this facility.

The $100-\mathrm{MeV}$ proton beams extracted from the main ring are delivered to the sub-critical fuel system constructed in the KUCA, as shown in Fig. 2. The proton beams are injected onto tungsten target installed at the end of a vacuum pipe of the beam transport line from the main ring, and it was located in front of the fuel system.

The past nuclear energy study has been mainly performed for nuclear reactors in critical state. The study about the nuclear characteristic for the system in sub-critical state, the condition of a nuclear reactor in which nuclear fuel no longer sustains fission chain reactions without external neutron source, has not been performed so much like in ADS. For example, the neutron flux and the neutron energy distribution in the core of ADS are very important physics quantities, but the precision of the calculation has not been fully evaluated. Although the estimation of the subcriticality; the measure of safety margin from critical state, is an important parameter for the safety operation of the system, the real time accurate measurement technique of subcriticality is below required level. In addition, there are many remaining research themes in ADS development such as the dynamic nuclear characteristics, and the nuclear stability at the injection and trip of the accelerator beam, and so on.

In these years in the Kyoto University, the following researches have been performed: 1) Proton beam profile measurements at the target (W) using Gafchromic Film (IPS Co); 2) measurements of production rate and angular distribution of neutrons generated by nuclear reactions of proton with $\mathrm{W}$; and 3) reaction rate measurements in the subcritical system by induced radioactivity in In and $\mathrm{Au}$ by changing various reactor parameters such as subcriticalty or neutron spectrum. Figure 3 shows an example of measured angular distribution of neutrons from the target in the ADS core.

Materials irradiation experiments in ADS condition (irradiation under protons and neutrons) at KUCA were also performed. Table 2 shows the change in the positron annihilation lifetime in metals near the tungsten target. Positron annihilation spectroscopy can be used to detect small vacant sites, which are below the resolution limit of transmission electron microscopy. Positron annihilation lifetimes of the specimens were measured at room temperature using a conventional fast-fast spectrometer with a time resolution of $190 \mathrm{ps}$ (full width at half maximum) until a total of $1 \times 10^{6}$ counts was reached. The positron lifetime spectra were analyzed using the PALSfit program [4] and, if possible, the lifetimes were decomposed into two components, $\tau_{1}$ and $\tau_{2}$. Otherwise, only a mean lifetime $\tau_{\mathrm{m}}$ was obtained. The long lifetime $\tau_{2}$ and its intensity $l_{2}$ indicate the size and concentration of defect clusters, respectively [5]. Au, Ni and model alloys of austenitic stainless steel (Fe-16Cr-17Ni, 
Fe-15Cr-16Ni-1.9Mn-2.7Mo,

Fe-15.27Cr-15.8Ni-1.88Mn-2.66Mo-0.53Si, Fe-15Cr-16Ni-1.9Mn-2.7Mo-0.53Si-0.24Ti), and commercial austnitic stainless steels (SUS 316L, SUS 316, SUS 304, Ti added SUS316) were irradiated. The composition of them is in Table 2. The lifetimes before irradiation were between 102 and 103 ps, which indicated no defects in the matrix. Although no effects were detected in high irradiation resistance metals such as commercial alloys, the lifetimes increased in $\mathrm{Au}, \mathrm{Ni}$ and $\mathrm{Fe}-16 \mathrm{Cr}-17 \mathrm{Ni}$, which indicated the formation of vacancy type defects.

\section{Materials irradiation effects}

The beam window and the ADS target are subjected to a very high irradiation load by source protons and spallation neutrons as well as neutrons generated inside the reactor. Spallation products also contribute to the damage evolution. In particular, the generation of $\mathrm{He}$ atoms causes heavy bubble formation because of a 10 times higher He/dpa ratio than that in fusion reactors. Another important feature is the large cascade formation [6]. Figure 4 shows the production of secondary particles by $150 \mathrm{MeV}$ protons calculated using event generator in the Particle and Heavy Ion Transport code System (PHITS) [7,8], which is an advanced Monte Carlo particle transport code such as MARS15 [9] and MCNPX [10]. Even for $150 \mathrm{MeV}$ protons, the secondary particles have high energy.

The beam window and target material of ADS experience severe thermal stress under on/off conditions of a high-intensity proton beam (>20 MW). Understanding the effect of this cyclic stress is essential for ADS construction. At present, there are no materials that enable the window to be operational for the desired period of time without deterioration of mechanical properties. Proton beam irradiation tests and thermal-hydraulic experiments are essential for the development of such structural materials. A preliminary stress-controlled cyclic deformation test of SUS316L was performed using a conventional tensile strength test instrument. The cyclic loading was tension-tension load control with a minimum stress of $90 \mathrm{MPa}$ and a maximum stress of $130 \mathrm{MPa}$ with a deformation period of approximately $6 \mathrm{~min}$. Deformations were performed in three conditions: 1) The deformation of nonirradiated specimen; 2) the in-situ deformation under $150 \mathrm{MeV}$ proton irradiation; and 3) post-irradiation deformation. After the cyclic deformation, positron annihilation lifetimes of the specimens were measured at room temperature as shown in Table 3. Even though the damage rate was low, the different of three conditions was detected. The mean lifetime of in-situ deformed SUS316L under irradiation is longest. The long lifetime of these specimens is almost equal to that of vacancies [11].

\section{Thermal hydraulics}

The spallation target and the beam window constitute the physical interface between the accelerator and the sub-critical reactor, and they are located in the core of the reactor. They are simultaneously subjected to severe thermo-mechanical loads (heat deposition densities) and irradiation-induced damage due to high-energy heavy particles. Thus, the spallation module should 
be designed based on optimization of the neutron yield, material properties and thermal-hydraulic performance while meeting the required safety and reliability conditions.

A solid water-cooled target consists of several target plates and cooling channels, which is certainly practical at relatively low beam powers. Of course, liquid-metal (mercury or lead bismuth) targets are also available for beam powers of $1 \mathrm{MW}$ and above [12]. According to some recent thermal-hydraulic research, $\gamma$-ray irradiation could affect wall wettability resulting in heat transfer enhancement in boiling conditions [13,14]. Normally, the solid target is cooled using subcooled water, and the water velocity in the cooling channel is very high, up to $10 \mathrm{~m} / \mathrm{s}$. In such flow conditions, micro-bubble emission boiling (MEB) may occur with relatively small heat transfer surfaces [15]. The purpose of this study is to investigate irradiation effects on the wall wettability and the boiling heat transfer enhancement, which may be encountered in the real ADS target system. Thus, the following issues are being investigated: 1) Effect of irradiation on wall wettability; 2) wettability effect on boiling heat transfer; and 3) effect of heat generation profile on boiling heat transfer.

Takamasa et al. investigated surface wettability using a metal oxide irradiated by $\gamma$-rays under normal room conditions [13]. The results showed that the surface wettability of oxidized metal pieces improved significantly by the Radiation Induced Surface Activation (RISA) phenomenon. Highly hydrophilic conditions of the test pieces were achieved after $500 \mathrm{kGy}$ irradiation using ${ }^{60} \mathrm{Co}$ $\gamma$-rays. However, no experiments have been carried out for ADS conditions. Using the FFAG accelerator, irradiation effects on wall wettability were investigated in this study. Figure 6 shows the wettability change before and after $100 \mathrm{MeV}$ proton irradiation with $4.7 \mathrm{nA}$ for $50 \mathrm{~h}$. The wettability on copper surfaces was enhanced by the proton irradiation regardless of the surface conditions.

\section{Concluding remarks}

ADS, which is being planned as a future neutron source for irradiation experiments and neutron scattering studies in KURRI, was introduced. Research and development for the evaluation of feasibility of ADS will be completed within 5 years for the FFAG accelerator, as well as materials irradiation effects, heat removal and subcritical reactor. Subsequently, after engineering design and approval of the supervisory government agency concerned (licensing), the construction of the prototype ADS is anticipated to start.

\section{Acknowledgements}

This study was a result of "Clarification of material behaviors in accelerator driven systems by an FFAG accelerator" carried out under the Strategic Promotion Program for Basic Nuclear Research by the Ministry of Education, Culture, Sports, Science and Technology of Japan. 


\section{References}

[1] C. H. Pyeon, T. Misawa, J. Y. Lim, H. Unesaki, Y. Ishi, Y. Kuriyama, T. Uesugi, Y. Mori, M. Inoue, K. Nakajima, K. Mishima, S. Shiroya,, J. Nucl. Sci. Technol., 46 (2009) 1091.

[2] Y.Mori, Proc. of IPAC2012, New Orleans, 2012. 1054.

[3] T. Uesugi, Y. Mori, H. Horii, Y. Kuriyama, K. Mishima, A. Osanai, T. Planche, S. Shiroya, M. Tanigaki, K. Okabe, I. Sakai, M. Inoue, Y. Ishi, M. Muto, Proc. of EPAC08, Genova, Italy, 2008.

[4] P. Kirkegaard, J.V. Olsen, M. Eldrup, N.J. Pedersen: Riso DTU, February 2009, ISBN: 978-87-550-3691-8, p. $44<$ http://palsfit.dk>.

[5] E. Kuramoto, T. Tsutsumi, K. Ueno, M. Ohmura, Y. Kamimura, Comp. Mater. Sci. 14 (1999) 28.

[6] T.Yoshiie, Y.Satoh and M.Kawai, Proceedings of the 11th International Symposium on Reactor Dosimetry, Aug. 18-23, 2002 Brussels, Belgium, ed. J.Wagemans, H.A.Abderrahim, P.D'hondt and C.D. Raedt.

[7] H. Iwase, K. Niita, T. Nakamura, J. Nucl. Sci. Technol. 39 (2002) 1142.

[8] Y. Iwamoto,K. Niita, T. Sawai, R.M. Ronningen, T. Baumann, Nucl. Instrum. Meth. B303 (2013) 120.

[9] Mokhov, S.I. Striganov, Proc. of Hadronic Shower Simulation Workshop, Fermilab, September 2006, AIP Conf. Proc. 896, pp. 50-60 (2007), http://www-ap.fnal.gov/MARS/.

[10] L.S. Water (Ed.), MCNPX Userees Manual version 2.4.0, LA-CP-02-408, Los Alamos National Laboratory, Los Alamos, New Mexico, 2002.

[11] T. Yoshiie, X.Z. Cao, Q.Xu, K. Sato, T.D. Troev, Phys. Status solidi, C6 (2009) 2333.

[12] Y. Saito, T. Hibiki, K. Mishima, T. Takeda, and F. Tanaka, ICONE-7, 7th Int. Conf. Nuclear Engineering, Tokyo, Japan, April 19-23 (1999), CD. No. FP7394.

[13] T. Takamasa, T. Hazuku, K. Okamoto, K. Mishima, M. Furuya, Exp. Therm. Fluid Sci., 29 (2005) 267.

[14] J. Zhang, K. Mishima, T. Hazuku, T. Takamasa, J. Nucl. Sci. Tec., 45 (2008) 541.

[15] K. Suzuki, Microgravity Sci. Tech., 19 (2007) 148. 
Table 1 Main parameters of the FFAG accelerator.

\begin{tabular}{ll}
\hline Number of sectors & 12 \\
Energy & $11-150 \mathrm{MeV}$ \\
Repetition rate & $20-120 \mathrm{~Hz}$ \\
Average beam current & $10 \mathrm{nA}$ \\
Radio frequency & $1.5-4.6 \mathrm{MHz}$ \\
Field index & 7.7 \\
Closed orbit radius & $4.4-5.3 \mathrm{~m}$ \\
\hline
\end{tabular}

Table 2 Positron annihilation lifetime measurement of metals irradiated in the KUCA with protons and neutrons $\left(2.7 \times 10^{11} \mathrm{n} / \mathrm{cm}^{2}\right)$. Only in $\mathrm{Au}$, the lifetime was decomposed into two components.

\begin{tabular}{|c|c|c|c|c|}
\hline Specimens & $\tau_{\mathrm{m}}(\mathrm{ps})$ & $\tau_{1}(\mathrm{ps})$ & $\tau_{2}(\mathrm{ps})$ & $\mathrm{I}_{2}(\%)$ \\
\hline$\overline{\mathrm{Au}}$ & $151 \pm 1$ & $111 \pm 1$ & $278 \pm 4$ & $23 \pm 1$ \\
\hline $\mathrm{Ni}$ & $106 \pm 1$ & & & \\
\hline Fe-16Cr-17Ni & $104 \pm 1$ & & & \\
\hline Fe-15Cr-16Ni-1.9Mn-2.7Mo & $103 \pm 1$ & & & \\
\hline Fe-15.27Cr-15.8Ni-1.88Mn-2.66Mo-0.53Si & $103 \pm 1$ & & & \\
\hline Fe-15Cr-16Ni-1.9Mn -2.7Mo-0.53Si-0.24Ti & $103 \pm 1$ & & & \\
\hline SUS $316 \mathrm{~L}$ & $102 \pm 1$ & & & \\
\hline \multicolumn{5}{|l|}{$(\mathrm{Fe}-17.35 \mathrm{Cr}-12.05 \mathrm{~N}-2.08 \mathrm{Mo}-0.85 \mathrm{Mn}-0.47 \mathrm{Si}-0.019 \mathrm{C}-0.027 \mathrm{P}-0.001 \mathrm{~S})$} \\
\hline SUS 316 & $102 \pm 1$ & & & \\
\hline \multicolumn{5}{|l|}{$(\mathrm{Fe}-19.22 \mathrm{Cr}-12.58 \mathrm{Ni}-2.26 \mathrm{Mo}-1.82 \mathrm{Mn}-0.39 \mathrm{Si}-0.05 \mathrm{C}-0.019 \mathrm{P}-0.004 \mathrm{~S})$} \\
\hline SUS 304 & $102 \pm 1$ & & & \\
\hline \multicolumn{5}{|l|}{$(\mathrm{Fe}-18.12 \mathrm{Cr}-9.08 \mathrm{Ni}-0.85 \mathrm{Mn}-0.48 \mathrm{Si}-0.05 \mathrm{C}-0.027 \mathrm{P}-0.002 \mathrm{~S})$} \\
\hline Ti added SUS316 & $104 \pm 2$ & & & \\
\hline$(\mathrm{Fe}-15.27 \mathrm{Cr}-15.8 \mathrm{Ni}-2.66 \mathrm{Mo}-1.88 \mathrm{Mn}-0.53 \mathrm{Si}-0.24 \mathrm{Ti}-0.055 \mathrm{C}-0.024 \mathrm{P})$ & & & & \\
\hline
\end{tabular}


Table 3 Positron annihilation lifetime measurements of cyclic deformed SUS316L. The damage rate was $5.2 \times 10^{-11} \mathrm{dpa} / \mathrm{s}$ and the total damage was $1.5 \times 10^{-6} \mathrm{dpa}$. Deformation period was approximately 6 min with a total of 80 cycles.

\begin{tabular}{lcccc}
\hline Specimen & Mean lifetime & Short lifetime & Long lifetime & $\begin{array}{c}\text { Long lifetime } \\
\text { intensity }\end{array}$ \\
& $\tau_{\mathrm{m}}(\mathrm{ps})$ & $\tau_{1}(\mathrm{ps})$ & $\tau_{2}(\mathrm{ps})$ & $\mathrm{I}(\%)$ \\
\hline Only cyclic deformation & $127 \pm 1$ & $82 \pm 3$ & $159 \pm 3$ & $54 \pm 4$ \\
In-situ deformation & $140 \pm 1$ & $75 \pm 3$ & $169 \pm 2$ & $64 \pm 2$ \\
Post-irradiation deformation & $131 \pm 1$ & $74 \pm 3$ & $159 \pm 2$ & $62 \pm 2$ \\
\hline
\end{tabular}

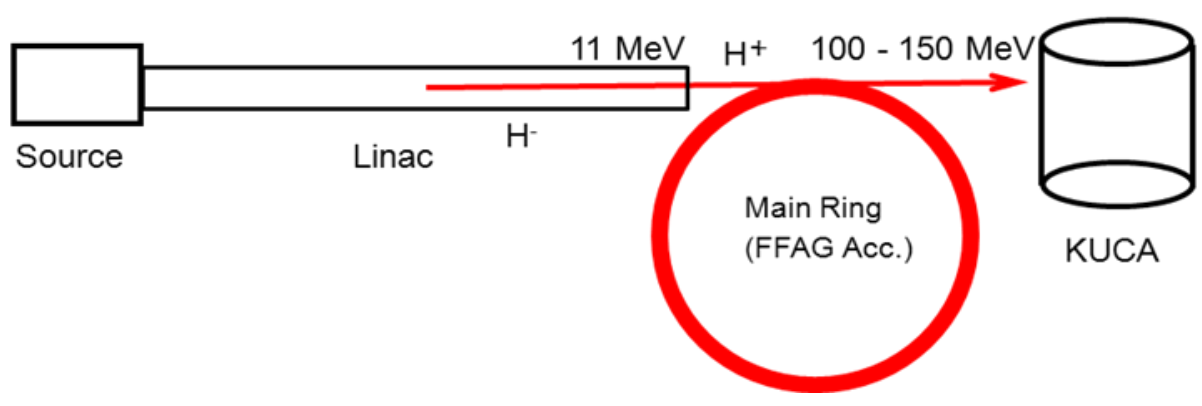

Figure 1 Configuration of the present FFAG complex.

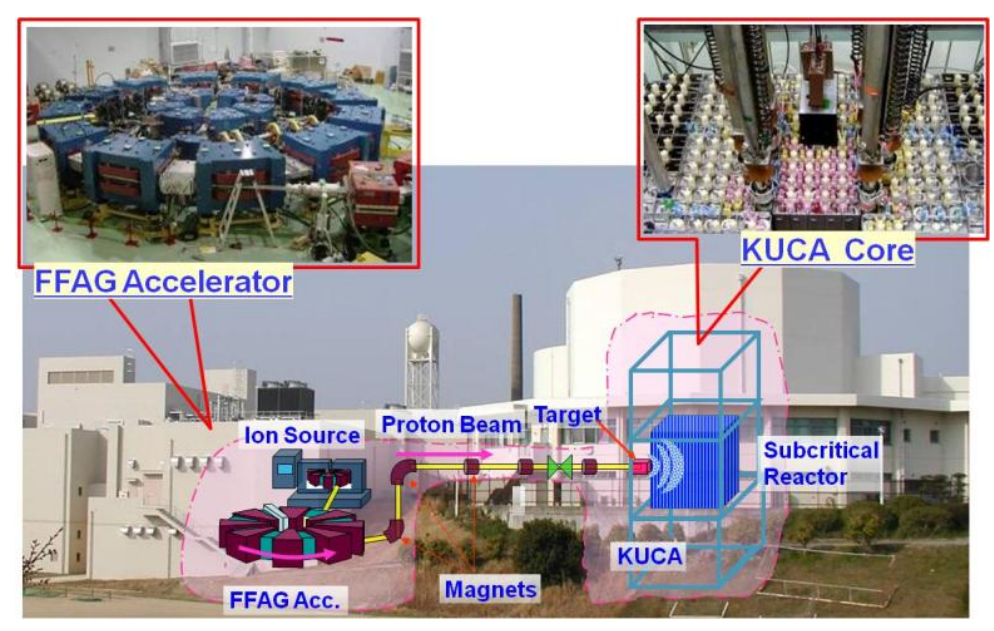

Figure 2 KUCA A-core and FFAG accelerator in the Research Reactor Institute at Kyoto University. 


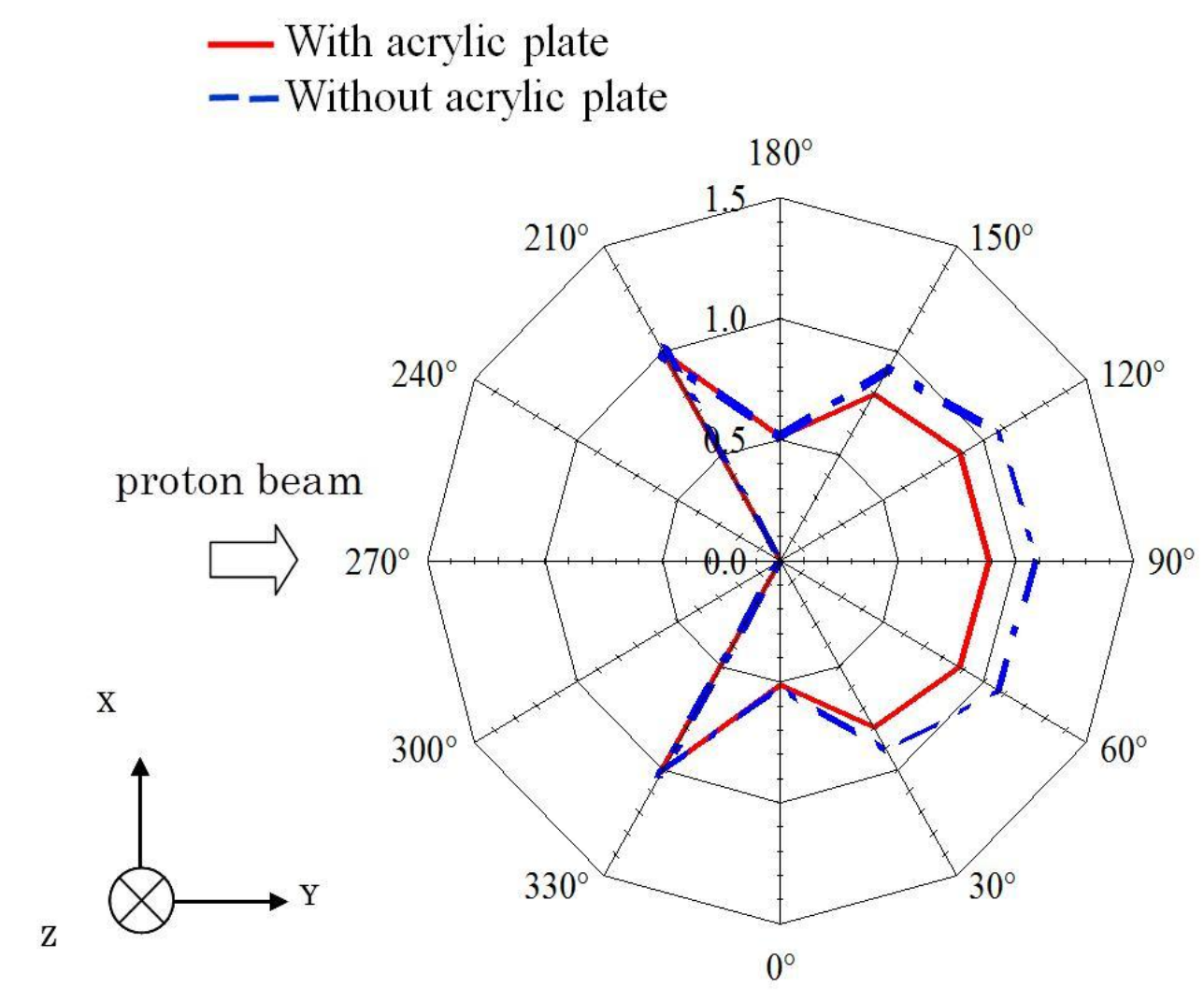

Figure 3 Measured angular distribution of produced neutrons by reaction of proton and $\mathrm{W}$ target in different conditions with and without a support acrylic plate.

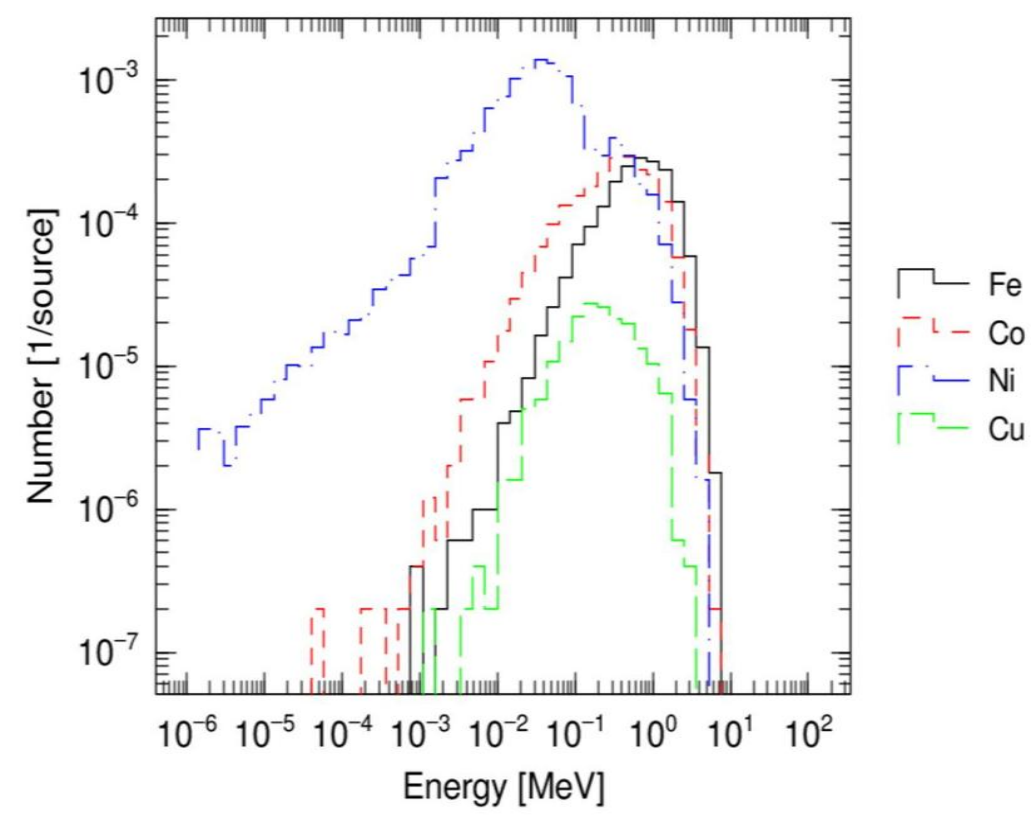

Figure 4 Production of secondary particles by $150-\mathrm{MeV}$ protons in Ni calculated using the PHITS code [7]. 


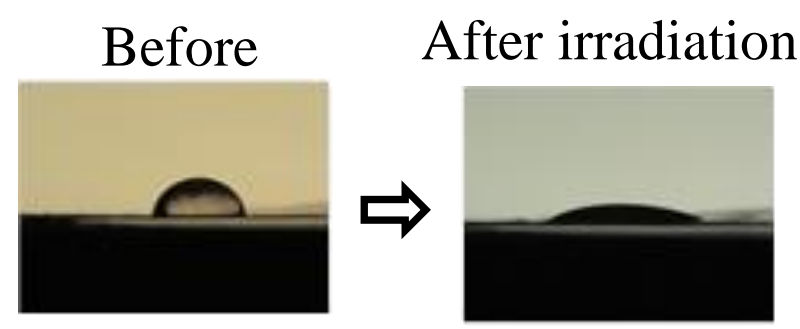

(a) Copper without oxide layer

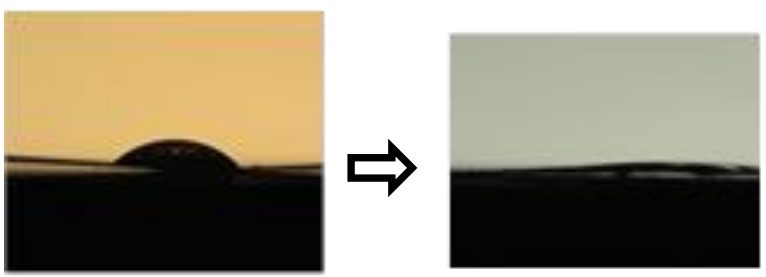

(b) Copper with oxide layer

Figure 5 Photographs of a water droplet before and after $100 \mathrm{MeV}$ proton irradiation on a copper surface. 